\title{
Artificial Neural Network Based DTC Driver for PMSM
}

\author{
Fatih Korkmaz, M.Faruk Çakır, smail Topaloğlu, Rıza Gürbüz \\ Çankırı Karatekin University, Technical and Business Collage, 18200, Çankırı, Turkey \\ e-mail:fkorkmaz@karatekin.edu.tr
}

\begin{abstract}
This paper deals with Direct Torque Control(DTC) of Permanent Magnet Synchronous Motors(PMSM's) with using artificial neural networks. PMSM's are increasing application areas such as traction, electric and hybrid vehicles, aerospace and servo systems due to its well-known advantages such as high power density, lower mass and volume. This paper investigates solution for the chronically and the biggest problem of the DTC scheme on the PMSMs: high torque ripple. Otherwise, another main problem faced in the DTC scheme is difficulties due to complex algorithm to get high performance control of motors for industrial applications. For this purpose, two different artificial neural networks have been suggested replacing the optimal switching vector selection and flux sector determination process of conventional direct torque control scheme. Matlab/Simulink based numerical simulations have been carried out to compare the PMSM performances with conventional control scheme and proposed artificial neural network based scheme.
\end{abstract}

\section{KEYWORDS}

Artificial neural networks, Direct torque control, PMSM control, Vector control

\section{INTRODUCTION}

Today vector controlled drives which named as FOC(field oriented control) and DTC are an industrial reality and are available on the market by many producers. In 1971, FOC first introduced for induction motors by Blasckhe[1] and it was completely unique for induction motors and in middle of 1980's, DTC has been proposed for induction motors by Takahashi [2] and similar idea that the name of Direct Self Control devoloped by Depenbrock [3]. Actually, the FOC and the DTC have rely on the same idea: vector control. Both of two schemes converts motors three phase components to two orthogonal vector components. So, it can be control like dc motors. controls motors by vectors but different methods. Unlike the FOC, the DTC does not require park transformation and any current regulator. Naturally, the DTC has also some disadvantages such as high current and torque ripples, variable switching frequency behaviour[4]. Many academically studies have been realized to avoid the DTC disadvantages and of course many of them still going on. We can group these studies under several headlines: The studies about different switching techniques and inverter topologies [5-6], the studies about artificial intelligence techniquies on different sections of system [7-8] and the studies about different observer models [9-10].

Although, the FOC and the DTC were proposed for induction motor, the both of them investigated and applied many other motor types such as brushless dc motors, switching 
reluctance motor and permanent magnet synchronous motors. PMSM's are increasing application areas such as traction, electric and hybrid vehicles, aerospace and servo systems due to its well known advantages like high power density, high efficiency, lightweight, small inertia, small volume, etc[11].

In this paper, we have presented a new artificial neural network DTC (ANN-DTC) scheme for the PMSMs to improve motor torque performance. For this purpose, two different artificial neural networks (ANNs) are educated and embedded to conventional DTC scheme. More detailed information about ANNs based scheme is presented in the following sections of the paper. The numerical simulations have been carried out with Mablab/Simulink software and the results of the methods are discussed and compared with the conventional DTC (C-DTC).

\section{DTC STRUCTURE}

In the DTC motor drive, the stator flux linkage and the electromagnetic torque can be directly controlled by the selection of optimum inverter switching states. The flux and torque errors are kept within acceptable limits by hysteresis controllers. The DTC allows for very fast torque responses, and flexible control of the induction motor[12]

The block diagram of DTC controlled motor is given in Fig. 1.

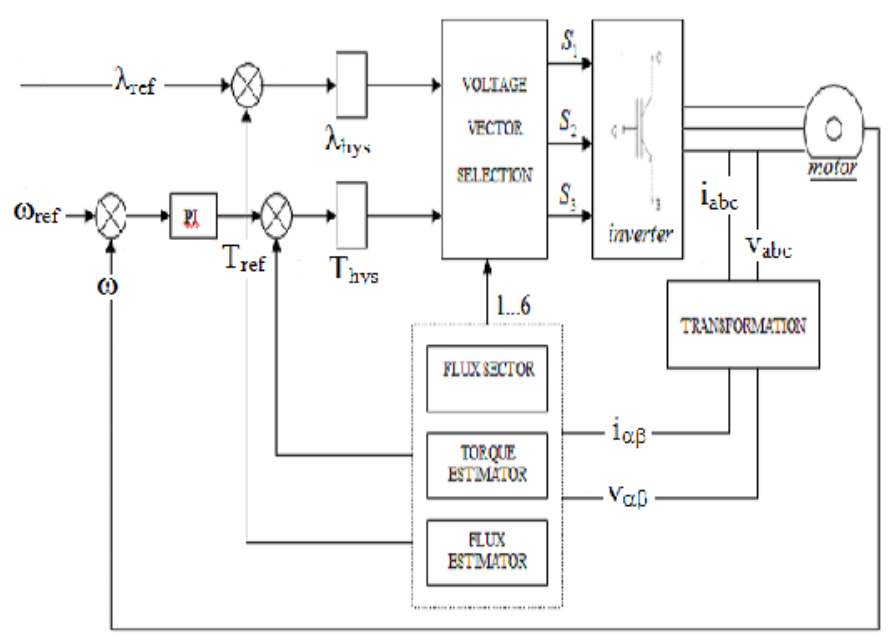

Figure 1. DTC controlled motor block diagram

Instantaneous values of the flux and torque are calculated by using the transformation of the measured currents and the voltages of the motor. The stationary reference frame (Clarke transformation) is used in the transformation. The Clarke transformation of the motor currents and voltages are shown as in Eq. 6-8.

$$
\begin{aligned}
i_{\alpha \beta 0} & =[T] \cdot i_{a b c} \\
V_{\alpha \beta 0} & =[T] \cdot V_{a b c}
\end{aligned}
$$




$$
T=\frac{2}{3}\left[\begin{array}{ccc}
1 & -\frac{1}{2} & -\frac{1}{2} \\
0 & -\frac{\sqrt{3}}{2} & \frac{\sqrt{3}}{2} \\
\frac{1}{2} & \frac{1}{2} & \frac{1}{2}
\end{array}\right]
$$

Where, $i_{a b c}$ and $V_{a b c}$ are measured in three phase currents and voltages, $i_{\alpha \beta 0}$ and $V_{\alpha \beta 0}$ are calculated in two phase currents and voltages. $\mathrm{T}$ is the transformation matrix. The stator flux is calculated as given in Eq.9-11 in an $\alpha-\beta$ reference frame.

$$
\begin{gathered}
\lambda_{\alpha}=\int\left(V_{\alpha}-R_{s} i_{\alpha}\right) d t \\
\lambda_{\beta}=\int\left(V_{\beta}-R_{s} i_{\beta}\right) d t \\
\lambda=\sqrt{\lambda_{\alpha}^{2}+\lambda_{\beta}^{2}}
\end{gathered}
$$

Where, $\lambda_{\alpha_{-}} \lambda_{\beta}$ stator flux, $i_{\alpha_{-}} i_{\beta}$ stator current, $V_{\alpha_{-}} V_{\beta}$ stator voltage $\alpha-\beta$ components, ${ }^{s_{s}}$ stator resistance. Motor torque calculations are as given in Eq.12.

$$
T_{e}=\frac{3}{2} p\left(\lambda_{\alpha} i_{\beta}-\lambda_{\beta} i_{\alpha}\right)
$$

Where, $\mathrm{p}$ is the motor pole pairs. The stator flux vector region is an important parameter for the DTC, and it can be calculated as given in Eq.13.

$$
\theta_{\lambda}=\tan ^{-1}\left(\frac{\lambda_{\beta}}{\lambda_{\alpha}}\right)
$$

The torque and flux errors, which are obtained by comparing the reference and observed values, are converted to control signals by hysteresis comparators. The switching table is used to determine the optimum switching inverter states, and it determines the states by using the hysteresis comparators outputs and the flux region data.

Switching states determining block creates inverter switching states and it has two input data as hysterezis comparator outputs and stator flux vector sector. Inverter switching states and stator flux vector sectors are defined as Fig. 2.

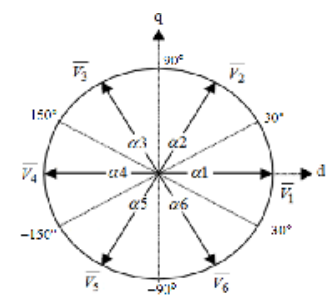

Figure 2. Inverter voltage vectors and sectors 


\section{ARTIFICIAL NeURAL NeTWORK BASED DTC}

ANNs have gaining interest ever past day in many fields including motion control, system modeling, parameter estimation and have been used modelling of non-linear systems in many kind of applications due to their unique abilities like processing of data at all network, learning ability and working with incomplete data etc. ANN-DTC scheme that we have proposed, has two different feed forward ANNs to select switching states and determine stator flux sector.

It must be pointed out that there is no certain rules about deciding and creating ANNs structure and system designers must be use trial and error method to decide optimum ANNs for their systems as we do. As a structure, both of proposed ANNs have a hidden layer with six neurons which decide by off-line training have been chosen. Stator flux sector determining ANN uses as input the 'd-axis stator flux' and ' $q$-axis stator flux'. Three layers of neuron are used as shown in Fig. 3.

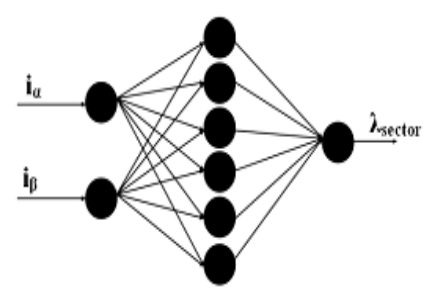

Figure 3. Stator flux sector determining ANN structure

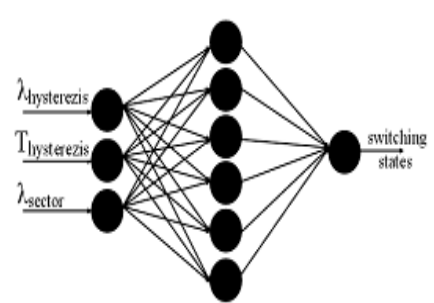

Figure 4. Switching states selection ANN structure

The second ANN is for the selection of inverter switching states as given in Fig.4, which is based on three inputs that flux and torque hysteresis comparators outputs and flux sector data which taken from the sector determining ANN output. Using of ANNs in proposed DTC scheme are given in Fig. 5.

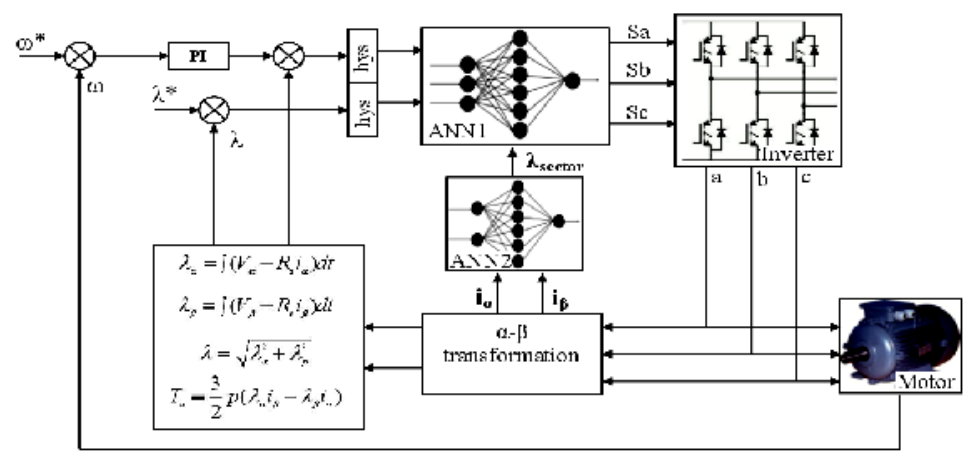

Figure 5. Proposed ANN based DTC scheme

\section{NUMERICAL SimULATIONS}

Numerical simulations have been carried out to investigate the effects the proposed ANN based DTC scheme. Its devoloped using Matlab/Simulink ${ }^{\circledR}$. The results of numerical simulation studies obtained in this work are for the PMSM and parameters of motor and simulations as given below. The machine model is implemented for C-DTC scheme and proposed ANN-DTC scheme 
using Matlab/Simulink. To compare performances with C-DTC and proposed ANN-DTC for PMSM rated speed applied to the motor under no load and then switch to loaded (10-Nm) condition at 0,5 . sec. The parameters of the PMSM and simulations, in SI units: U $=300 \mathrm{~V}$, $\mathrm{T}=10 \mathrm{Nm}, \mathrm{n}=2300 \mathrm{rpm}, \mathrm{Rs}=0.4578 \quad$, Sampling Time $=100 \mu \mathrm{s}$.

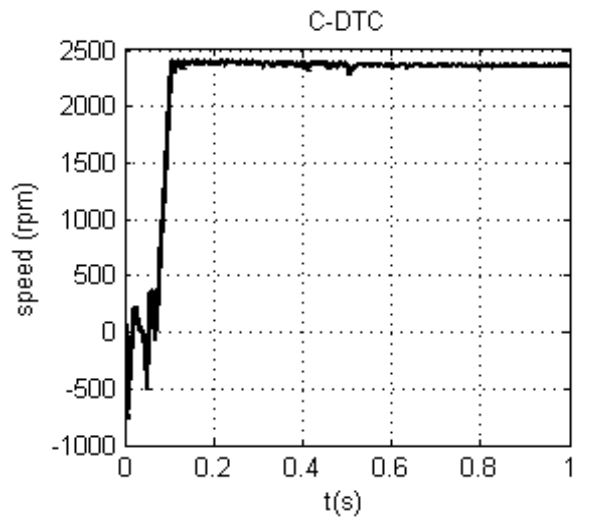

Figure 6. C-DTC speed response

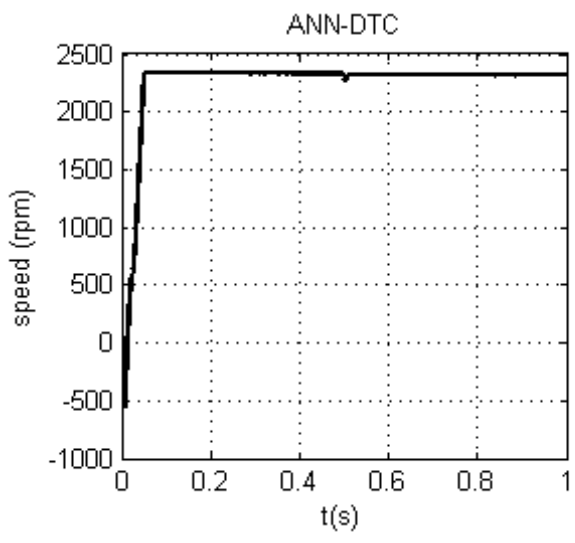

Figure 7. ANN-DTC speed response

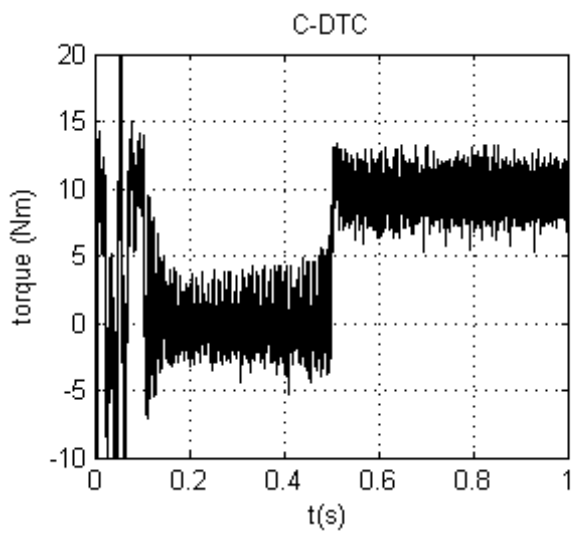

Figure 8. C-DTC torque response 


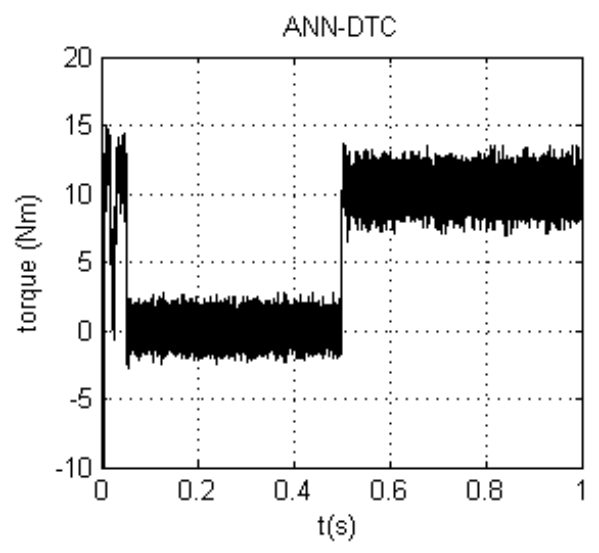

Figure 9. ANN-DTC torque response

Fig. 6 and Fig. 7 shows speed responses of the motor with the C-DTC and the ANN-DTC working conditions. It can be seen that the ANN-DTC controlled motor speed ripples are lesser with loaded and unloaded conditions when compared the C-DTC controlled one. The torque responses of the C-DTC and the ANN-DTC controlled motors are shown in Fig. 9 and Fig. 10. It can be seen that the motor ripple in torque response is reduced with ANN-DTC for loaded and unloaded conditions.

\section{CONCLUSION}

This paper presents ANN based control structure on the DTC scheme for PMSM drives to find solution for high torque ripple that is the chronically and the biggest problem of the DTC scheme. The secondary aim of this paper is to simplify the control structure by using ANNs learning abilities and to investigate the affects of this structure on torque performance of motor. For these aims, two different ANNs have been designed for flux sector determining and the switching voltage vector selection on the DTC scheme and this new scheme investigated for the PMSM motor drive. The proposed ANN-DTC scheme performance is compared with the conventional DTC scheme at rated speed and different load conditions. The ANN-DTC scheme performance has been tested by numerical simulations. The ANN-DTC technique which is shown as dynamic responses are the faster in transient state and the torque ripple in steady state are reduced remarkably when compared with the conventional DTC for loaded and unloaded conditions. Besides, complex mathematical structure of C-DTC has been simplified with learning abilities of ANN's. The simulation results support that the proposed ANN based DTC scheme is a good alternative to the conventional DTC controlled PMSM drives.

\section{REFERENCES}

[1] F. Blaschke, "The Principle of Field Orientation Applied to The New Transvector Closed LoopControl System for Rotating Field Machines” Siemens-Rev., vol.39, pp. 217-220, 1972.

[2] I. Takahashi and T. Noguchi , "A new quick-response and high efficiency control strategy of an induction motor" IEEE Transactions on Industrial Applications, vol.I A-22, no.5, pp. 820-827, 1986.

[3] M. Depenbrock, "Direct self control of inverter-fed induction machines" IEEE Transactions in Power Electronics, vol. PE-3, vo. 4, pp. 420-429, 1988.

[4] Z. Chunhua and C. Xianqing, "Direct Torque Control Based on Space Vector Modulation with Adaptive Neural Integrator for Stator Flux

[5] D. Casadei, G. Serra and A. Tani, "The use of matrix converters in direct torque control of induction machines" IEEE Trans. on Industrial Electronics, vol.48, no.6, pp. 1057-1064, 2001. 
International Journal of Instrumentation and Control Systems (IJICS) Vol.3, No.1, January 2013

[6] D. Casadei, G. Serra and A. Tani, "Implentation of a direct torque control algorithm for induction motors based on discrete space vector modulation" IEEE Trans. on Power Electronics, vol.15, no. 4, pp. 769-777, 2000.

[7] S. Benaicha, F. Zidani, R.-N. Said, M.-S.-N. Said, “ Direct Torque with Fuzzy Logic Torque Ripple Reduction Based Stator Flux Vector Control“" Computer and Electrical Engineering, (ICCEE '09), vol.2, pp. 128-133, 2009.

[8] N. Sadati, S. Kaboli, H. Adeli, E. Hajipour and M. Ferdowsi, "Online Optimal Neuro-Fuzzy Flux Controller for DTC Based Induction Motor Drives" Applied Power Electronics Conference and Exposition (APEC 2009),- P.210-215. 2009.

[9] Z. Tan, Y. Li and Y. Zeng, "A three-level speed sensor-less DTC drive of induction motor based on a full-order flux observer" Power System Technology, Proceedings. PowerCon International Conference, vol. 2, pp. 1054- 1058, 2002.

[10] G. Ya and L. Weiguo, "A new method research of fuzzy DTC based on full-order state observer for stator flux linkage" Computer Science and Automation Engineering (CSAE), 2011 IEEE International Conference, vol. 2, pp.104-108, 2011.

[11] Singh, J.; Singh, B.; Singh, S.P.; Naim, M.; , "Investigation of performance parameters of PMSM drives using DTC-SVPWM technique," Engineering and Systems (SCES), 2012 Students Conference on , vol., no., pp.1-6, 16-18 March 2012

[12] P. Vas, "Sensorless vector and direct torque control" - Oxford University Press, 2003. 